\title{
Unresectable Recurrent Multiple Meningioma: A Case Report with Radiological Response to Somatostatin Analogues
}

\author{
Ana Ortolá Buigues ${ }^{a} \quad$ Irene Crespo Hernández ${ }^{a}$ \\ Manuela Jorquera Moya ${ }^{b}$ Jose Ángel Díaz Pérez ${ }^{a}$ \\ ${ }^{a}$ Servicio de Endocrinología y Nutrición, Hospital Clínico San Carlos, Madrid, Spain; \\ ${ }^{\mathrm{b}}$ Servicio de Radiodiagnóstico, Hospital Clínico San Carlos, Madrid, Spain
}

\section{Keywords}

Meningioma $\cdot$ Octreotide $\cdot$ Somatostatin $\cdot$ Somatostatin receptors $\cdot$ Meningeal neoplasms

\begin{abstract}
Medical treatment of meningiomas is reserved for cases in which surgery and radiotherapy have failed. Given that a high percentage of meningiomas express somatostatin receptors, treatment with somatostatin analogues has been proposed. In addition, these medications have been shown to have an antiproliferative and antiangiogenic effect in vitro. To date, very few cases with clinical response and none with radiological response have been described. The case described here is the first to report a radiological response. A 76-year-old Caucasian male was first diagnosed with unresectable meningioma at age 47 . The patient experienced multiple recurrences and underwent three surgeries and radiotherapy over the years from the initial diagnosis. Despite treatment, the disease continued its progression. Based on an Octreoscan positive for tumour uptake, therapy with extended-release somatostatin analogues was started. Although no clinical neurological improvement was observed, magnetic resonance imaging scans revealed a discreet but continuous radiological response over time. After $>2$ years of continuous administration of lanreotide, the patient remains progression free. In highly selected cases, somatostatin analogue treatment for meningioma may be ben-
\end{abstract}


eficial. Based on our findings, treatment with somatostatin analogues should be maintained longer than previously described before evaluating treatment response.

\author{
(c) 2016 The Author(s) \\ Published by S. Karger AG, Basel
}

\title{
Introduction
}

Meningiomas are the most common primary brain tumours in adults [1]. The vast majority of these $(90 \%)$ are benign (grade I) tumours, with the rest classified as atypical (grade II) or anaplastic (grade III) tumours, according to the World Health Organization. The treatment of choice is surgery, which is curative in $90 \%$ of cases when complete resection is achieved. In unresectable or inoperable tumours, treatment options include radiotherapy or radiosurgery [2]. However, in a small percentage of patients, neither surgery nor radiotherapy is successful, resulting in disease recurrence or tumour progression. In such cases, the only remaining treatment option is medical therapy, although response to current medications is, at best, only partial [3-5]. For this reason, research into alternative treatments, including somatostatin analogues, is ongoing [6-10].

It has been reported that up to $90 \%$ of meningiomas express somatostatin receptors, a fact that has generated much interest in the use of somatostatin analogues [11-13]. The reported antiproliferative and antiangiogenic effect of these drugs has further increased their potential attractiveness [14], although this is partially tempered by the results of one study that found that somatostatin analogues might stimulate the proliferative activity of meningiomas in vitro [15]. The most common receptor subtype in these tumors is somatostatin receptor 2A (sstr2A) [16], and elevated levels of this receptor are associated with greater angiogenesis in atypical, anaplastic and microcytic meningiomas $[17,18]$. The presence of somatostatin receptors can be detected by octreotide scintigraphy (Octreoscan) and immunohistochemical study, and patients with high levels of sstr2A expression are potential candidates for treatment with somatostatin analogues.

Despite the promise of somatostatin analogues, few studies have investigated the use of this therapeutic approach in meningioma. Moreover, of the studies that have been carried out, only a few have reported a clinical response [19-21] and none have found a radiological response. Here we report the case of a patient with recurrent multiple meningioma who presented a clear radiological response to treatment with somatostatin analogues and who remains progression free after more than 2 years of treatment.

\section{Case Presentation}

The patient was a 76-year-old Caucasian male with a long history of recurrent multiple meningiomas. The patient's previous medical history includes hypertension, dyslipidemia, and lower acute myocardial infarction at age 44 . At age 47, the patient was first diagnosed with right parietal parasagittal meningioma involving the falx cerebri, which was treated with surgery. Twenty years later, due to progression of residual left-sided hemiparesis, the patient was diagnosed with a recurrence for which he underwent a second surgery at age 68 . This second surgical resection was incomplete, leaving a thin layer of tumour tissue in the posterior third of the sagittal sinus. Histopathology was compatible with meningothelial meningioma. Magnetic resonance imaging (MRI) of the posterior brain showed multiple early recurrences ( 2 parasaggital, 1 parietal, and 1 frontoparietal). Due to progression of 
these lesions, a third surgery was performed 3 years later, at age 71 . This surgery resulted in multiple postoperative complications, the most important of which were a cerebrospinal fluid fistula requiring a ventriculopleural shunt, repeated failed graft reconstructions due to infections, and an intestinal perforation (due to a laparotomy performed to obtain a microvascular omental graft) leading to peritonitis and, subsequently, right hemicolectomy.

Sixteen months after the third surgery, a follow-up MRI showed clear signs of disease progression, with multiple extra-axial lesions involving the falx cerebri. After multidisciplinary assessment, the patient was referred for radiotherapy. Three months following radiotherapy treatment, radiological examination revealed a new progression, with growth in the maximal diameter of the sum of the lesions (from 8 to $8.4 \mathrm{~cm}$ ). The patient's long history of recurrent meningiomas, along with three surgeries and radiotherapy, has left him with important sequelae, including left hemiparesis and partial seizures (since the second surgery), currently being treated with anticonvulsant therapy.

Given the patient's extensive history of recurrent meningiomas and progression after radiotherapy, various medical treatment options were considered. After much deliberation, we elected to initiate compassionate-use treatment with extended-release somatostatin analogues. This decision was based on the previously performed Octreoscan showing positive uptake on the somatostatin receptors, and published reports of clinical response to this medication, which is also reported to be well tolerated. We prescribed subcutaneous injection of lanreotide (Somatuline Autogel ${ }^{\circledR}$ ) at a dose of 120 mg every 28 days due to the convenience of this delivery method. Brain MRIs performed every 6 months thereafter revealed a discreet but continuous radiological improvement. Given these findings, we maintained medical treatment without interruption to the present time (currently $>2$ years of treatment). At exactly 2 years from treatment initiation with lanreotide, the volume of the lesions had decreased by approximately $35 \%$. Clinically, the patient continues to receive rehabilitation for neurological deterioration.

\section{Discussion}

Medical treatment of meningiomas is reserved as a final option in cases in which surgery and radiotherapy have been ruled out or have failed. Chemotherapy, immunotherapy, hormonal therapy, and biological therapies have all been described and remain under study [3-5], although none of these treatments has managed to achieve more than a partial response.

Although the expression of somatostatin receptors in meningiomas was first reported in 1986 [11], only a small number of case reports and studies have investigated the use of somatostatin analogues for this type of cancer. The first case of meningioma treated with octreotide was published in 1989 in the journal Lancet [19]. In that case report, a patient diagnosed with an inoperable (due to comorbidities) pituitary macroadenoma with intrasellar extension (later diagnosed on histopathological evaluation as meningioma) received octreotide treatment at 2 years after diagnosis. The patient presented a clinical response to treatment, including fewer headaches and improvement of his visual field, but no radiological response was observed. In 1993, another report described three cases of unresectable meningioma treated with octreotide. While clinical improvement was observed in two cases, no radiological response was found in any of the three cases [20]. However, the authors of that study noted that the lack of radiological response could have been attributable to the short treatment duration ( 8 weeks maximum) or insufficient doses. More recently (2007), a 
pilot clinical trial [21] was conducted in 16 patients with recurrent meningiomas treated with extended-release somatostatin analogues. Of these 16 patients, $31 \%$ had a partial response (clinical or radiological response $<25 \%$ ), 31\% had stable disease, and 37\% experienced disease progression. Progression-free survival (PFS) at 6 months was $44 \%$. Based on these findings, the authors concluded that somatostatin analogues may offer a novel, relatively nontoxic alternative treatment for recurrent meningiomas. In contrast, a phase II clinical trial involving 11 patients with recurrent or progressive meningiomas treated with octreotide found no clinical or radiological response in any of the patients [22]. Mean time to progression was 17 weeks, mean survival was 2.7 years, and only 2 patients had a long PFS. That study, however, had an important limitation: no Octreoscan was performed before or after treatment, and subsequent immunohistochemical analysis for sstr2 was positive in only 6 patients. The most recent report involved a phase II clinical trial [10] in which 9 patients with high-grade meningiomas were treated with octreotide after a positive Octreoscan. However, none of the patients achieved a partial radiological response (defined as a decrease of $>50 \%$ ) and median PFS was 4-5 months.

Although some of the studies described above reported a clinical response in some patients, none found a radiological response. Importantly, all these studies share a common limitation: short treatment duration. By contrast, our patient received $>2$ years of lanreotide treatment, with no disease progression in this period. While we cannot rule out possible effects from prior radiotherapy in our patient (radiotherapy treatment was completed 4 months before the start of medical treatment), the finding of disease progression on the MRI performed after radiotherapy suggests that it is unlikely that the radiological response is attributable to radiotherapy.

Despite the negative results of the two clinical trials described above, the case report we present here suggests that some patients could benefit from treatment with somatostatin analogues. Moreover, treatment duration may play an important role. Although we did not observe a clinical response in our patients, the radiological improvement was sufficient to achieve more than 2 years of PFS in a patient whose tumour, although low grade, showed clear signs of clinical aggressiveness, particularly in recent years.

\section{Conclusions}

The findings reported here in a patient treated with lanreotide for more than 2 years suggest that treatment with somatostatin analogues should be maintained longer than previously described before treatment response is evaluated. In highly selected cases of meningioma, somatostatin analogues may be beneficial. However, at present, selection of patients most likely to benefit from this treatment is hindered by the lack of specific imaging tests and biochemical/molecular markers. Studies with longer treatment duration and larger sample sizes would help to clarify this situation.

\section{Acknowledgements}

The authors wish to thank Bradley Londres for his assistance in translating and editing the text, and Ipsen Pharma S.A. for providing funding for these services. 
Ortolá Buigues et al.: Unresectable Recurrent Multiple Meningioma: A Case Report with Radiological Response to Somatostatin Analogues

\section{Statement of Ethics}

Written informed consent was obtained from the patient for publication of this case report and any accompanying images. A copy of the written consent is available for review by the Editor of this journal.

\section{Disclosure Statement}

J.A. Díaz Pérez declares receiving payments for lectures paid for by Ipsen Pharma S.A. The remaining authors declare that they have no competing interests. The translation and editing of this manuscript was funded by Ipsen Pharma S.A., who also paid for the article processing charges related to publication.

\section{References}

1 Claus EB, Bondy ML, Schildkraut JM, Wiemels JL, Wrensch M, Black PM: Epidemiology of intracranial meningioma. Neurosurgery 2005;57:1088-1095.

- Krengli M, Apicella G, Deantonio L, Paolini M, Masini L: Stereotactic radiation therapy for skull base recurrences: is a salvage approach still possible? Rep Pract Oncol Radiother 2015;20:430-439.

3 Wen PY, Quant E, Drappatz J, Beroukhim R, Norden AD: Medical therapies for meningiomas. J Neurooncol 2010;99:365-378.

4 Sioka C, Kyritsis AP: Chemotherapy, hormonal therapy, and immunotherapy for recurrent meningiomas. J Neurooncol 2009;92:1-6.

5 Alexiou GA, Markoula S, Gogou P, Kyritsis AP: Genetic and molecular alterations in meningiomas. Clin Neurol Neurosurg 2011;113:261-267.

6 Kaley TJ, Wen P, Schiff D, Ligon K, Haidar S, Karimi S, Lassman AB, Nolan CP, DeAngelis LM, Gavrilovic I, Norden A, Drappatz J, Lee EQ, Purow B, Plotkin SR, Batchelor T, Abrey LE, Omuro A: Phase II trial of sunitinib for recurrent and progressive atypical and anaplastic meningioma. Neuro Oncol 2015;17:116-121.

7 Mawrin C, Chung C, Preusser M: Biology and clinical management challenges in meningioma. ASCO Educ Book ASCO Meet 2015;35:e106-e115.

-8 Du Z, Abedalthagafi M, Aizer AA, McHenry AR, Sun HH, Bray M-A, Viramontes O, Machaidze R, Brastianos PK, Reardon DA, Dunn IF, Freeman GJ, Ligon KL, Carpenter AE, Alexander BM, Agar NY, Rodig SJ, Bradshaw EM, Santagata S: Increased expression of the immune modulatory molecule PD-L1 (CD274) in anaplastic meningioma. Oncotarget 2015;6:4704-4716.

-9 Miller R, DeCandio ML, Dixon-Mah Y, Giglio P, Vandergrift WA, Banik NL, Patel SJ, Varma AK, Das A: Molecular targets and treatment of meningioma. J Neurol Neurosurg 2014;1:1000101.

-10 Simó M, Argyriou AA, Macià M, Plans G, Majós C, Vidal N, Gil M, Bruna J: Recurrent high-grade meningioma: a phase II trial with somatostatin analogue therapy. Cancer Chemother Pharmacol 2014;73:919-923.

11 Reubi JC, Maurer R, Klijn JG, Stefanko SZ, Foekens JA, Blaauw G, Blankenstein MA, Lamberts SW: High incidence of somatostatin receptors in human meningiomas: biochemical characterization. J Clin Endocrinol Metab 1986;63:433-438.

12 Reubi JC, Lang W, Maurer R, Koper JW, Lamberts SW: Distribution and biochemical characterization of somatostatin receptors in tumors of the human central nervous system. Cancer Res 1987;47:57585764.

13 Klutmann S, Bohuslavizki K, Brenner W, Behnke A, Tietje N, Kröger S, Hugo H, Mehdorn H, Clausen M, Henze E: Somatostatin receptor scintigraphy in postsurgical follow-up examinations of meningioma. J Nucl Med 1998;39:1913-1917.

14 Reubi JC, Laissue JA: Multiple actions of somatostatin in neoplastic disease. Trends Pharmacol Sci 1995;16:110-115.

15 Cavalla P, Schiffer D: Neuroendocrine tumors in the brain. Ann Oncol 2001;12(suppl 2):S131-S134.

-16 Schulz S, Pauli SU, Schulz S, Händel M, Dietzmann K, Firsching R, Höllt V: Immunohistochemical determination of five somatostatin receptors in meningioma reveals frequent overexpression of somatostatin receptor subtype sst2A. Clin Cancer Res 2000;6:1865-1874. 


\section{Case Reports in Oncology}

Ortolá Buigues et al.: Unresectable Recurrent Multiple Meningioma: A Case Report with Radiological Response to Somatostatin Analogues

17 Barresi V, Alafaci C, Salpietro F, Tuccari G: Sstr2A immunohistochemical expression in human meningiomas: is there a correlation with the histological grade, proliferation or microvessel density? Oncol Rep 2008;20:485-492.

-18 Durand A, Champier J, Jouvet A, Labrousse F, Honnorat J, Guyotat J, Fèvre-Montange M: Expression of cMyc, neurofibromatosis Type 2, somatostatin receptor 2 and erb-B2 in human meningiomas: relation to grades or histotypes. Clin Neuropathol 2008;27:334-345.

19 Rünzi MW, Jaspers C, Windeck R, Benker G, Mehdorn HM, Reinhardt V, Reinwein D: Successful treatment of meningioma with octreotide. Lancet 1989;1:1074

20 García-Luna PP, Relimpio F, Pumar A, Pereira JL, Leal-Cerro A, Trujillo F, Cortés A, Astorga R: Clinical use of octreotide in unresectable meningiomas. A report of three cases. J Neurosurg Sci 1993;37:237241.

21 Chamberlain MC, Glantz MJ, Fadul CE: Recurrent meningioma: salvage therapy with long-acting somatostatin analogue. Neurology 2007;69:969-973.

22 Johnson DR, Kimmel DW, Burch PA, Cascino TL, Giannini C, Wu W, Buckner JC: Phase II study of subcutaneous octreotide in adults with recurrent or progressive meningioma and meningeal hemangiopericytoma. Neuro Oncol 2011;13:530-535. 